\title{
Compression ignition of $\mathrm{Hydrogen}\left(\mathrm{H}_{2}\right)$ in a direct injection diesel engine Modified to operate as a Low Heat Rejection
}

\author{
Shaik Syed meer ${ }^{1 *}$, Mahes Mallampati ${ }^{2}$, A. $\operatorname{RamaRao}^{3}$, \\ Sobhanadri Anantha ${ }^{4}$, P. Balu ${ }^{5}$ \\ ${ }^{1 * 23}$ Department of Mechanical Engineering, Guntur Engineering College, Guntur, Andra \\ Pradesh, India \\ ${ }^{4}$ Department of Mechanical Engineering, Chalapathi Institute of Technology, Guntur, \\ Guntur, Andhra Pradesh, India. \\ ${ }^{5}$ Department of Automobile Engineering, Bharath Institute of Higher Education and \\ Research, Chennai, Tamil Nadu. \\ Corresponding author: balu.auto@bharathuniv.ac.in
}

\begin{abstract}
Global pollution levels in many applications will now be at danger because of the growing need for fuel. CR hydrogen is an alternative to diesel fuel and a possible supply of unspent fuel in India. Using hydrogen as a sole fuel in a direct-injection diesel engine has been tested for its practicality. One-cylinder diesel engine with air cooling was adapted to operate as a low-heat-rejection engine. To protect the engine's combustion chamber, partially stabilized zirconia ceramic components were employed. A single-cylinder compression ratio $(C R)$ engine with varied CR Hydrogen fuels will be studied to determine the optimal performance and emission characteristics. There was a comparison of diesel fuel performance measures such as specific fuel consumption (SFC), brake thermal efficiency (BTE), and emissions of HC, CO, Smoke, and NOx. A compression ratio of 17.5 for hydrogen fuel demonstrates higher performance and reduced emissions, which is quite similar to neat diesel fuel in terms of performance and emissions levels. Different compression ratios (15.5, 16.5, and 17.5) were tested in order to determine the optimal combination for running the engine on hydrogen mixes. Furthermore, the increase in compression ratio raises the BTE, reduces the SFC, and lowers emissions without any engine design changes.
\end{abstract}

Key words: Hydrogen, Compression Ignition Engine, Low heat Rejection, Compression Ratios.

\section{Introduction}

Hydrogen has long been considered a potential transportation fuel for the piston engine because of its many attractive combustion characteristics. As a fuel, hydro- gen has two distinct advantages over fossil fuel:

(1) It is a renewable energy storage medium.

(2) Absence of carbon dioxide in its combustion products.

Concern over environmental damages resulting from fossil fuel combustion generated pollution and uncertain fossil fuel supply further helped to promote hydrogen as a possible 
alternative fuel for these engines in the future [1]. One of several reasons why hydrogen has not already supplanted oil is that it costs too much to produce. The production of hydrogen from various energy sources including hydro- and nuclear electricity during offpeak- load period had been suggested. The key is to find a technique for the efficient electrolysis of water because existing electrolysers are too inefficient to produce large quantities of hydrogen as cheaply as fossil fuel on a per energy unit basis. However, that could change with the advancement made by the Commission of the European Communities on novel catalysts that make the electrodes more efficient. Aside from production cost, hydrogen presents some very challenging problems in the fields of storage and utilization. Numerous studies had been carried out to use hydrogen as fuel in spark ignition carburetor type engines and diesel engines designed with a pre chamber and either a spark or glow plug to assist initiation of combustion [2]. Investigated using homogeneous hydrogen air mixtures in reciprocating piston engines. They concluded that significant chemical reactions begin when the charge temperature reaches $550 \mathrm{~K}$ during the compression stroke and that all reaction ceases below $850 \mathrm{~K}$ during expansion [3]. Suggested that the self-ignition temperature of hydrogen is $858 \mathrm{~K}$. This is very close to the value of $844 \mathrm{~K}$, which is normally quoted as the auto- ignition temperature of hydrogen under the most favorable conditions [4]. The objective of the present study was to investigate compression ignition of injected gaseous hydrogen and its related problems in a production engine which was modified to operate in a low-heat-rejection mode. Extreme care was exercised to ensure that neither lubricant combustion nor hot spots existed in the combustion chamber before performing the tests.

\section{Materials and Methods}

\subsection{Low Heat Rejection Engine}

In diesel engines, increasing the combustion temperature improves efficiency and reduces emissions. This necessitates the use of heat-resistant materials for the combustion chamber components. Adding a ceramic coating to these components can improve their hightemperature resistance. It has been proven that alternative fuels emit less pollution when burned at higher temperatures. In addition, the coating acts as a thermal barrier to reduce the amount of heat that is transmitted through the combustion chamber [5]. In internal combustion engines, only a tiny portion of the total energy from burning is transformed into usable energy. In order to preserve engine parts from overheating, friction and exhaust, more than half of this energy is lost through the cooling system. By reducing the specified losses, the engine's useful work may be increased most effectively. A material with poor thermal conductivity and strong thermal resistance under extreme temperatures should be used or coated on sections of the combustion chamber to achieve this. Recently, ceramic-coated engine components have been utilized. Study's goal was to improve the engine's performance and make the engine parts more resistant to wear and corrosion. Plasma spray coating is used to provide heat barrier coatings to cylinder heads, pistons, and valves. Ceramic coatings protect these parts against wear, friction, heat, corrosion, and oxidation. Using low-quality fuel was achievable because the combustion chamber temperature was greater in the ceramic coated engines than in the uncoated engines. Dessication will also cause a decrease in the 
amount of energy that the cooling system removes, which will lead to a greater temperature in the combustion chamber following compression [6].

Plasma spray coating was used to coated the cylinder head, valve, and piston of the test engine with $0.5 \mathrm{~mm}$ thick zirconia.

\subsection{Coating Process}

Plasma spraying is the spraying of molten or heat softened material onto a surface in order to produce a coating or protection against corrosion. Zuerst wird an extremely high temperature plasma flame used to rapidly heat and accelerate zirconia powder to a high speed. After impacting the substrate, the hot substance rapidly cools, leaving behind a coating. As a heat source, an electric arc was maintained in the nozzle of the plasma spraying method. Inert gases are heated to a very high degree by the arc. The gas molecules are dissociated and ionized as a result of the high temperature. Gas volume increases dramatically when heated to high temperatures, causing it to flow at an extremely high velocity (plasma jet). Using a carrier gas, a powdered coating substance is pumped into the feed unit from the feed unit. These particles melt and adhere to the surface of the treated base material as a protective layer when heated. It is shown in Figure 1 that a low heat rejection engine uses zirconiacoated piston, cylinder head and valve components.

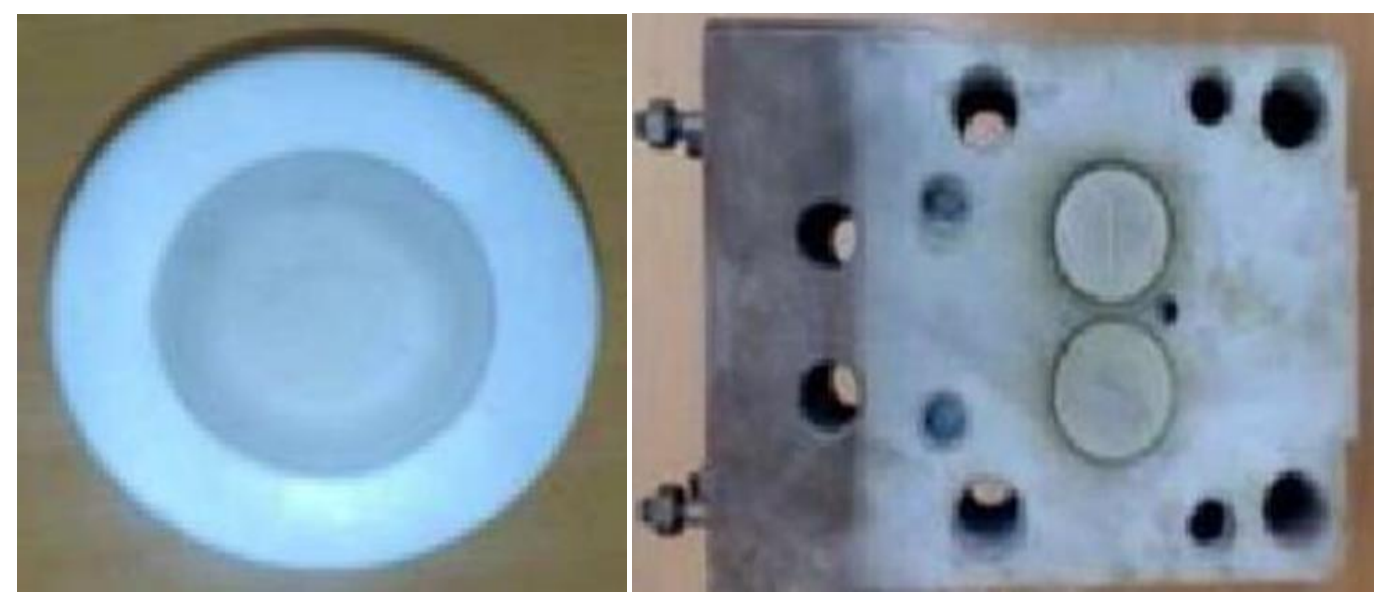

Figure 1. Zirconium coated piston, cylinder head and valves

Table 1 Properties of Hydrogen and diesel

\begin{tabular}{|l|c|c|}
\hline \multicolumn{1}{|c|}{ Properties } & Hydrogen & Diesel \\
\hline Density $\left(\mathrm{kg} / \mathrm{m}^{3}\right.$, at $\left.20^{\circ} \mathrm{C}\right)$ & 0.08375 & 820 \\
\hline Flash point $\left({ }^{\circ} \mathrm{C}\right)$ & $\begin{array}{c}\text { Flammable } \\
\text { gas }\end{array}$ & 68 \\
\hline Auto ignition temperature $\left({ }^{\circ} \mathrm{C}\right)$ & 560 & $300-340$ \\
\hline Lower heating value $(\mathrm{MJ} / \mathrm{kg})$ & 119.96 & 43 \\
\hline Cetane number & 53.2 & 42 \\
\hline Vapor pressure $\left(\mathrm{kPa}\right.$ at $\left.38^{\circ} \mathrm{C}\right)$ & 11.9 & 0.34 \\
\hline Latent heat of vaporization $(\mathrm{kJ} / \mathrm{kg})$ & 455 & 620 \\
\hline
\end{tabular}




\section{Experimental setup}

Figures 2 depict the experimental setup utilized in this study a single-cylinder fourstroke engine with a 17.5:1 compression ratio and $4.4 \mathrm{~kW}$ at $1500 \mathrm{rpm}$, connected to a variable-resistance generator. There was a 200bar injector rating and a static injection timing of $23^{\circ}$ BTDC on the engine. Checked gasoline level in tank, water flow, and oil level in engine oil sump before starting the engine. After starting the engine, it was warmed up. All engines ran at their rated speeds. Current and voltage measurements were used to determine the engine's power output. To measure the cooling water temperature, a thermocouple with a digital temperature indication was utilized. One of the piezoelectric sensors measured the pressure in the tank. QROTECH exhaust gas analyzer analyzed CO, NOx, and HC emissions. We utilized a TI Diesel Tune smoke meter to measure the amount of smoke. No load and full load loads were used in the studies.

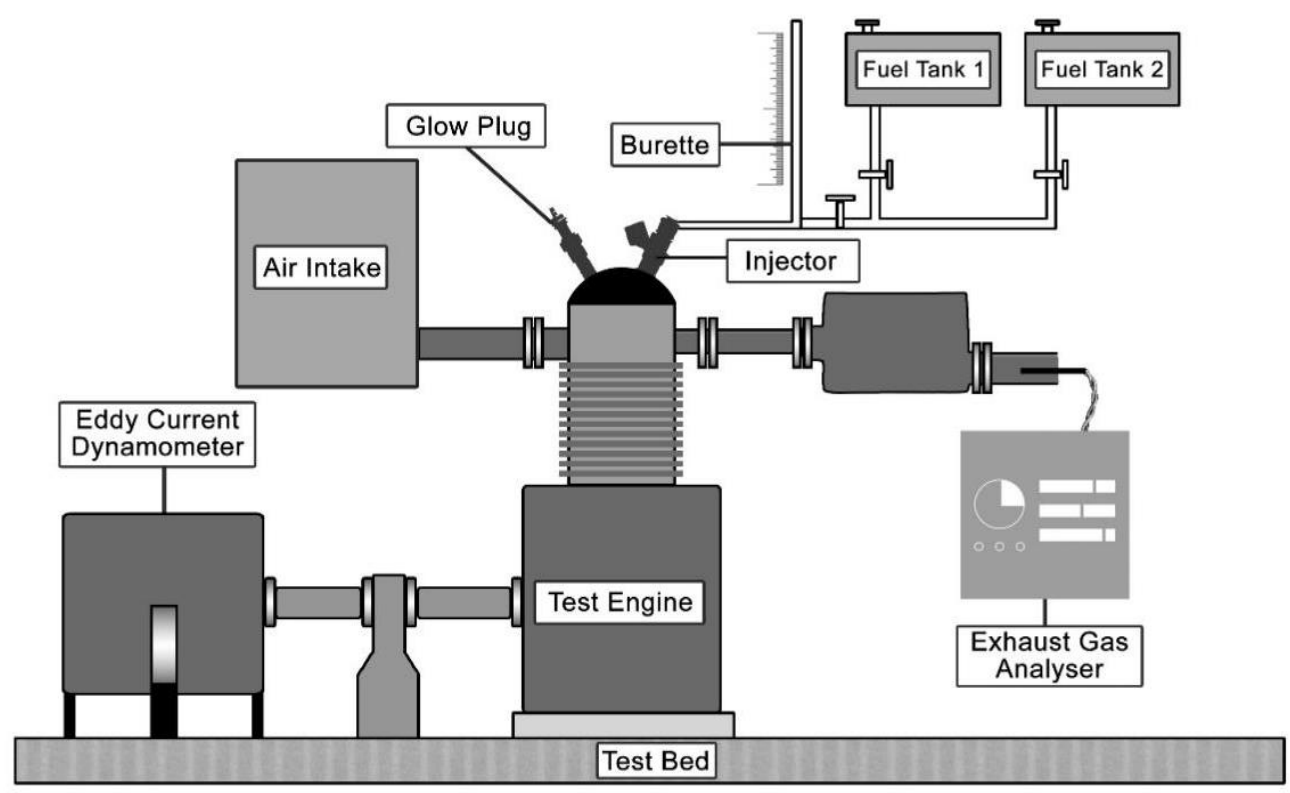

Figure 2. Schematic view of experimental setup

\section{Result and Discussion}

\subsection{Brake Thermal Efficiency}

According to Fig. 3, various CR with LHR engines have varied braking thermal efficiency. There are three distinct CR hydrogen+ LHR brake thermal efficiency percentages for normal engines with ceramic coating: 29, 20, 26, 52 and 25, respectively (see figure). To prevent thermal transmission from an engine to its environment, a partly stable Zirconia brake has better thermal efficiency than ceramic coatings. Reduced heat loss boosts engine power and thermal efficiency as a result [7]. 


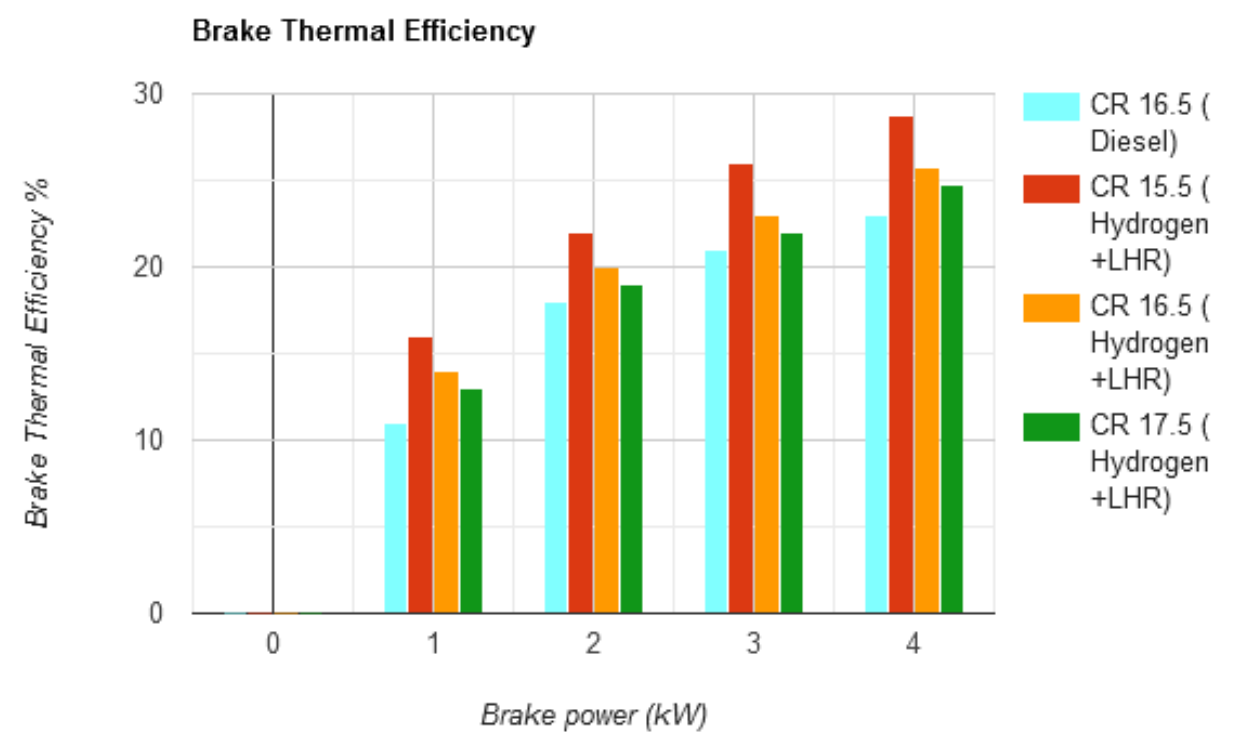

Figure 3. Brake power vs Brake Thermal Efficiency

\subsection{Brake Specific Energy Consumption}

Internal combustion engines waste a lot of usable energy by cooling and exhausting it. The image 4 shows the discrepancy in the usage of specific fuel energy for standard and CR Hydrogen in LHR engines. It was 5.63 percent and 3.21 percent lower in CR 17.5 Hydrogen + LHR than ordinary diesel fuel, respectively. With a high mix percentage, the SFC rises. This is related to the biodiesel's density, viscosity, and thermal value. Despite this, the SFC increases with a lower compression ratio because to the sluggish combustion.

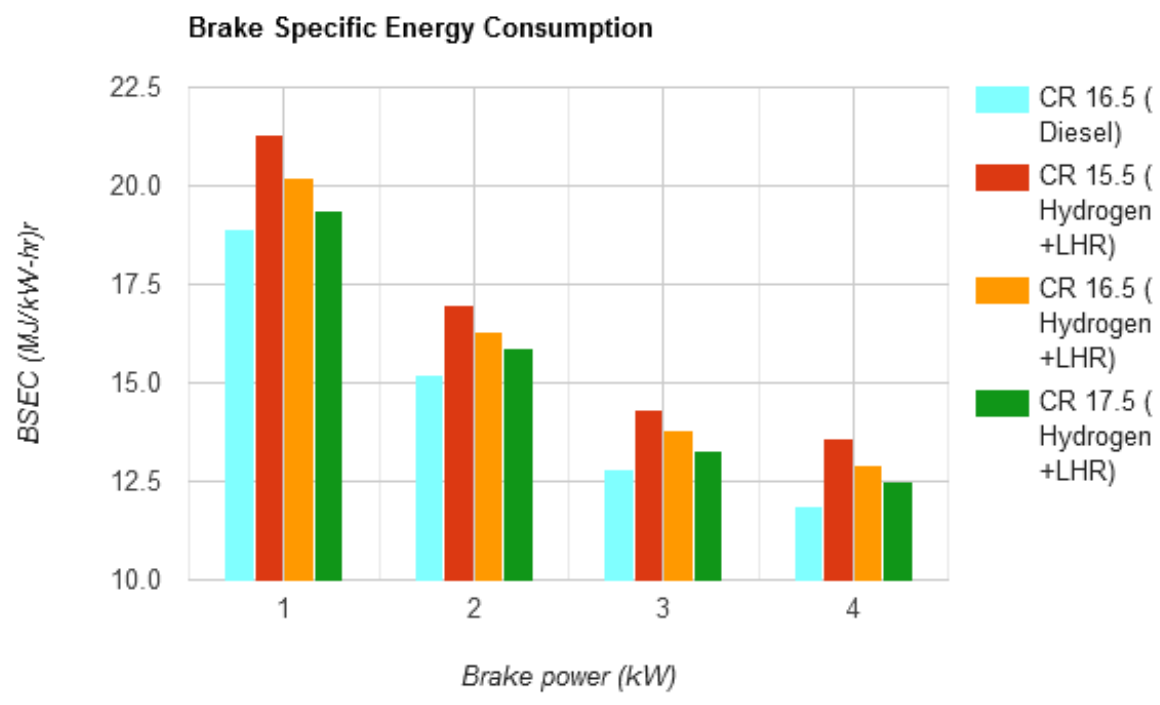

Figure 4. Brake power vs Brake Specific Energy Consumption

\subsection{Carbon Monoxide Emission}

There's a figure in Figure 5. Carbon monoxide emissions for CR diesel and CR hydrogen + LHR load engines are compared. When compared to the CR diesel engine and the CR hydrogen + LHR, CO emissions were reduced by 15.3 percent and 10.2 percent, respectively. Due to the idolatrous effects of hydrogen pumped into the chamber, fuel vaporizes faster [8]. 


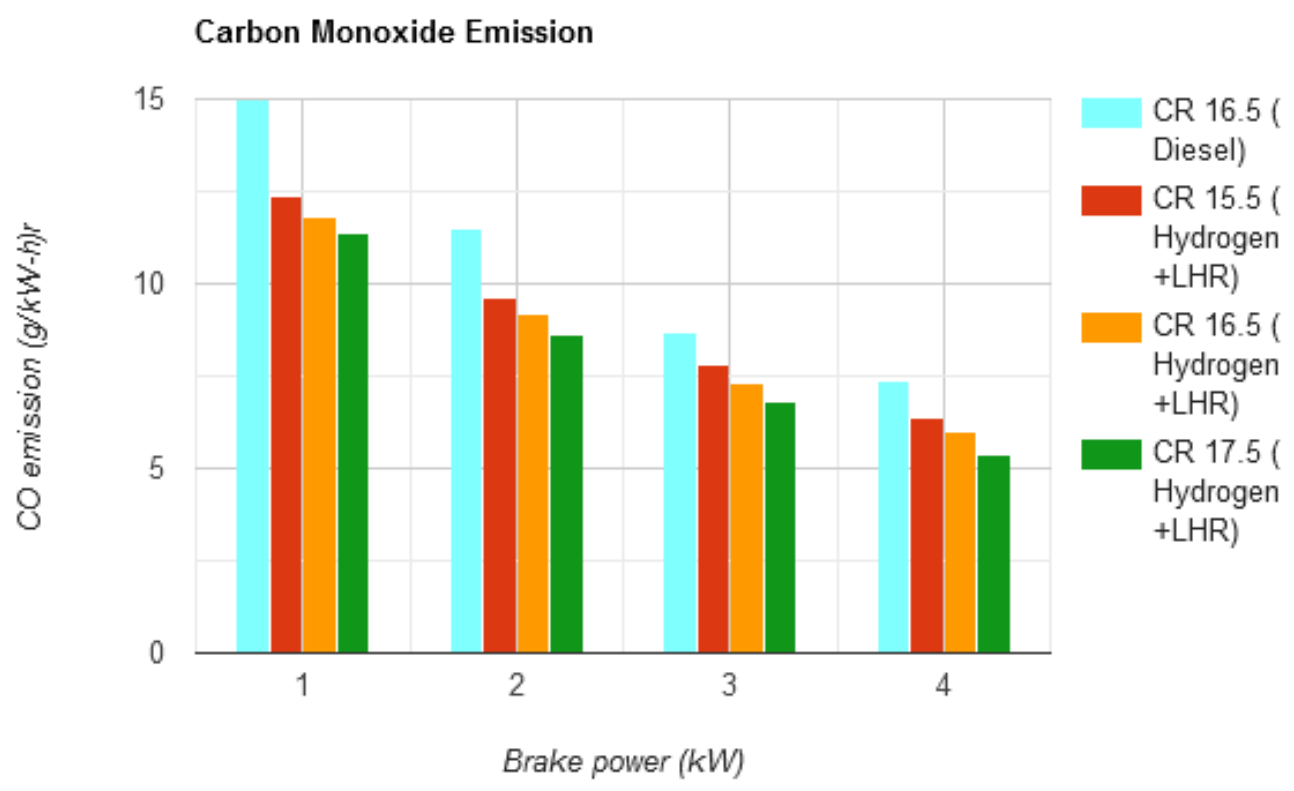

Figure 5. Brake power vs Carbon Monoxide Emission

\subsection{Unburnt Hydrocarbon Emission}

Figure 6. Displays UBHC as a load in CR diesel and CR hydrogen + LHR. The figure indicates that the LHR engine was less than the hydrocarbon emissions of the conventional engine. LHR was fueling UBHC's hydrogen emissions at full load conditions. The CR diesel and CR hydrogen + LHR engine was 8.74 percent lower and the standard uncoated engine was 5.32 percent lower than the usual, and CR 17.5 hydrogen + LHR. The decrease in HC emissions on the coated engine is due to the increase in post-combustion temperature due to reduced cooling heat loss, which contributes to additional combustion of more UBHC [9].

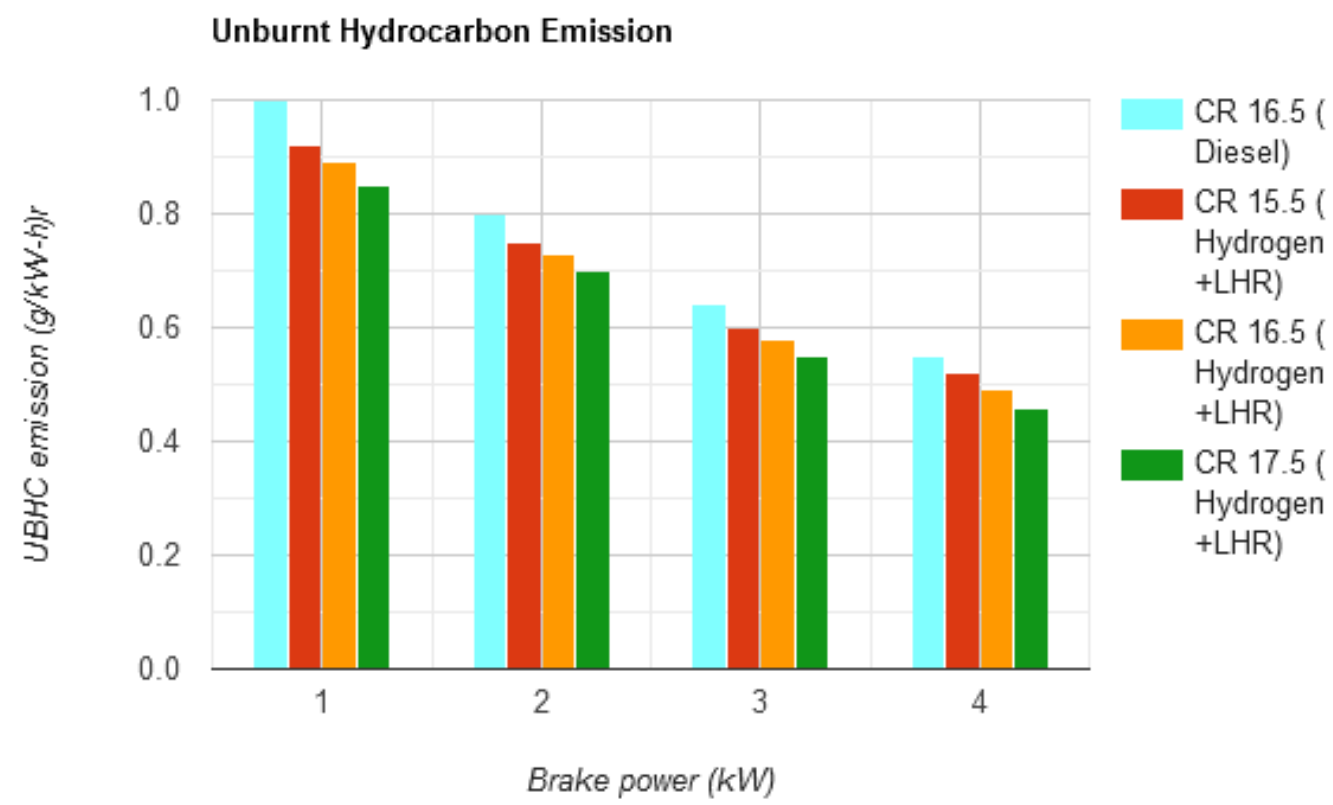

Figure 6. Brake power vs Unburnt Hydrocarbon Emission 


\subsection{Oxides of Nitrogen Emission}

Fig. 7. The load difference for CR diesel and CR hydrogen + LHR display nitrogen-emission oxides. CR 17.5 Hydrogen + LHR NOx emissions have been fuel low heat rejection of 12.34 per cent, and an increase of 17.53 per cent for CR hydrogen + LHR in comparison with the diesel engine. The increased NOx emissions to the coated engine could boost the zirconia coating temperature after combustion [10].

Oxides of Nitrogen Emission

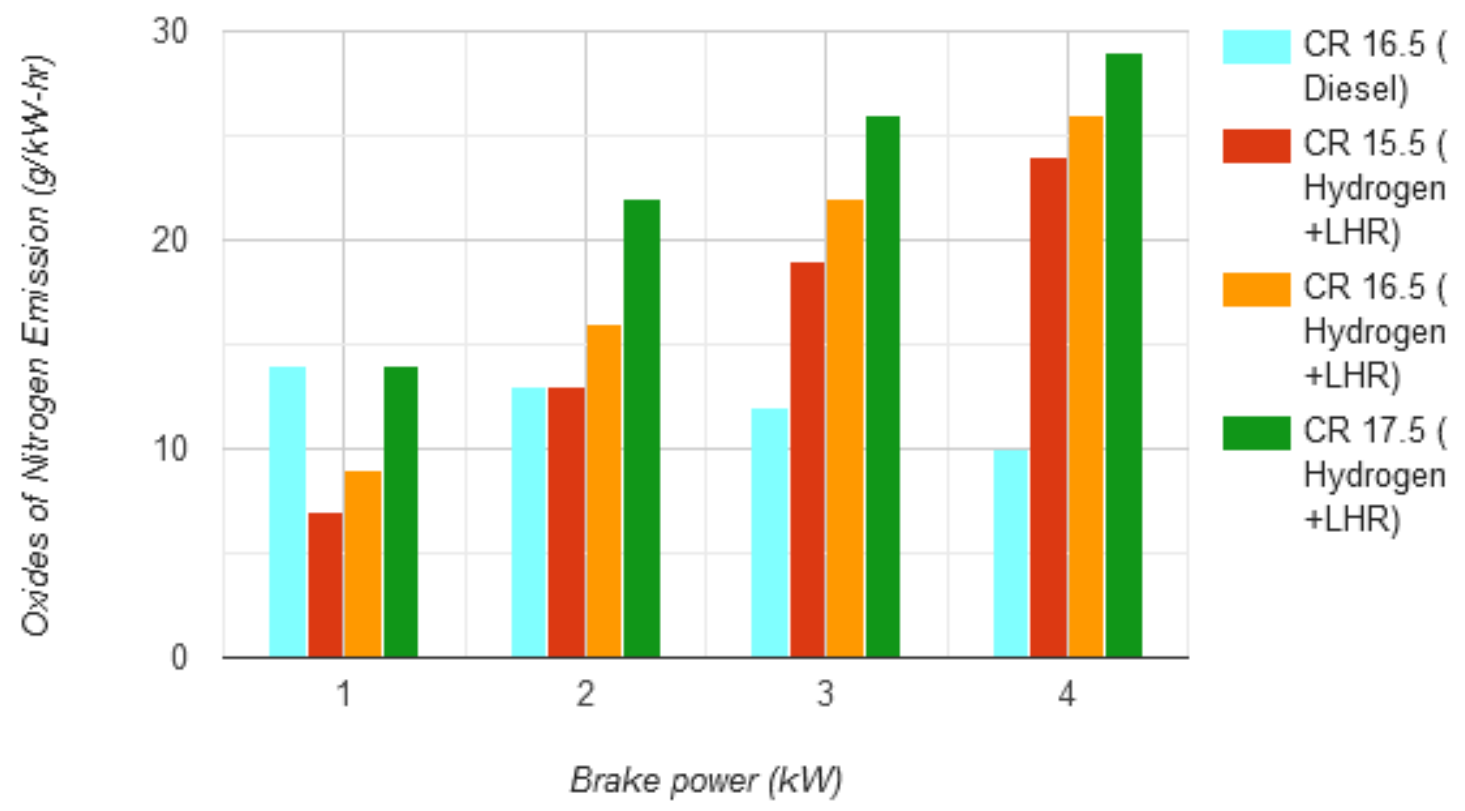

Figure 7. Brake power vs Oxides of Nitrogen Emission

\subsection{Smoke Opacity}

Figure 8. Shows CR diesel and CR hydrogen + LHR smoke emission variations in load. At load speed, Hydrogen was fuelled by a low-heat rejection, which was CR 17.5 by $5.65 \%$ and $15.28 \%$ and compared with the normal CR hydrogen + LHR. Due to the sectional thermal barrier and more carbon particles, higher temperature occurred in the incinerator. Smoke emissions, as already suggested, are caused by incomplete carbon particles combustion. Combustion chamber coating increases burning efficiency due to increased combustion chamber temperatures [11]. 


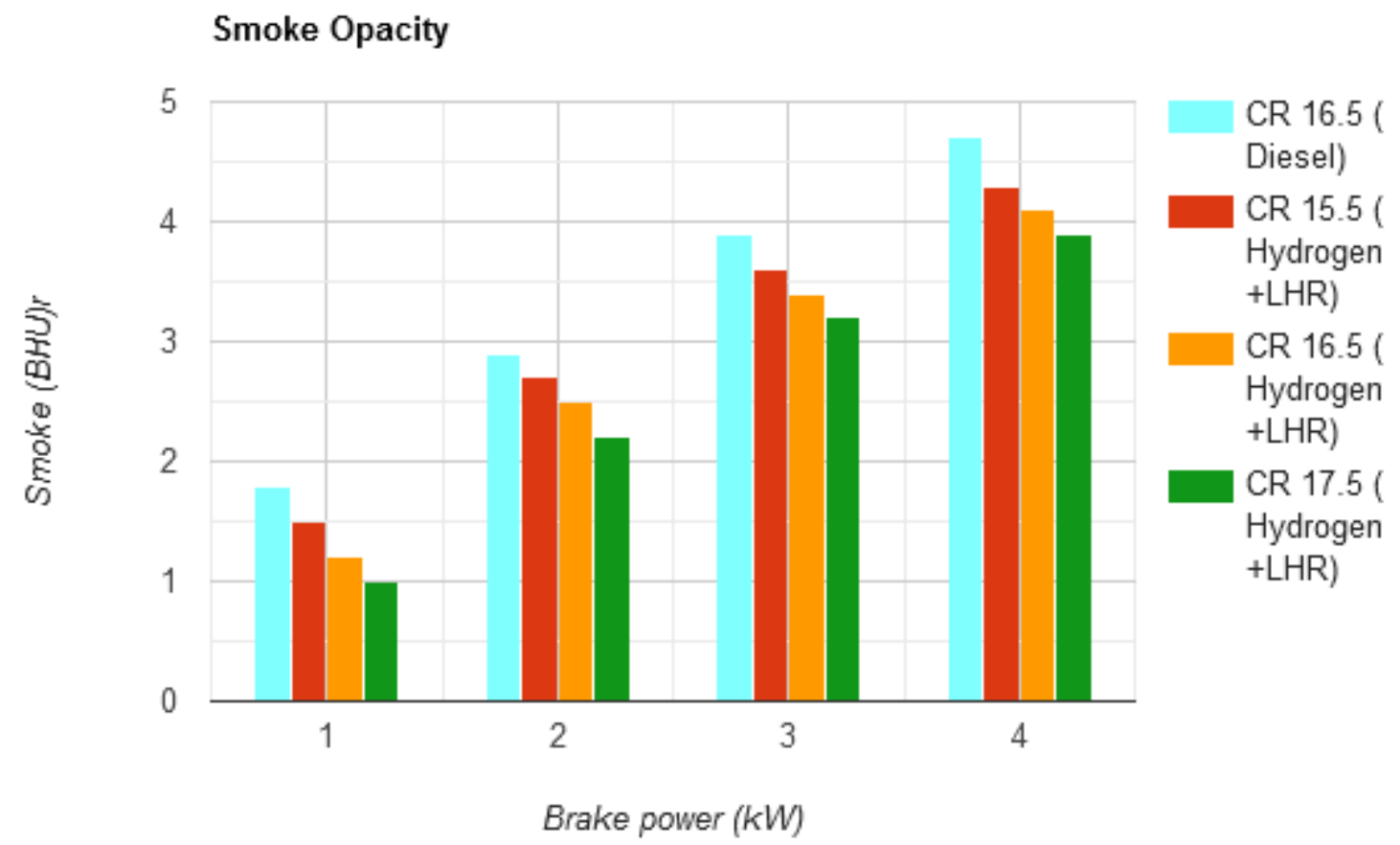

Figure 8. Brake power vs Smoke Opacity

\subsection{Cylinder Pressure}

Figure 9 shows the CR diesel and CR hydrogen + LHR cylindrical pressure engine with regard to the crank angle. The total pressure rises with increased engine load. The increased CR hydrogen + LHR 17.5bar engine temperature induces a maximum stress of 73.4 bar in a conventional $\mathrm{CI}$ engine after TDC (71.5 bar), which is similar to diesel $\left(13^{\circ} \mathrm{CA}\right)$. After zirconia has been coated with hydrogen, the maximum pressure increased dramatically due to the increased temperature, accelerating the in-cylinder burning process. The cylinder's high pressure gives better burning and heat release [12].

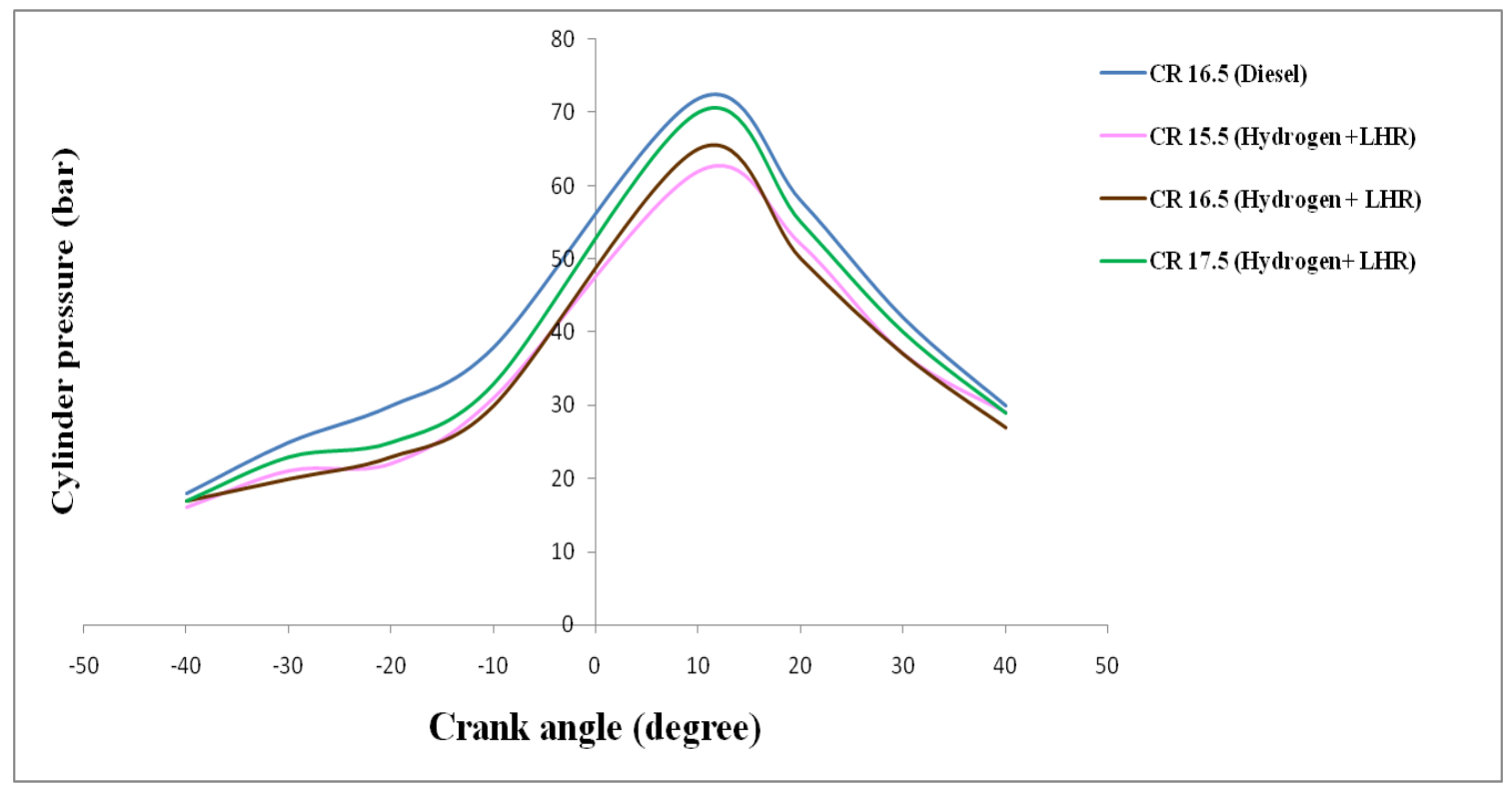

Figure 9.Crank angle vs Cylinder Pressure 


\subsection{Heat Release}

Illustration 10 shows the CR diesel and CR hydrogen + LHR cylinder pressure test results as far as the crank angle is concerned. The Hydrogen was obvious heat release rate was lower than that of clean diesel fuel, considering the fact that CR hydrogen with LHR atomized and vaporized less than fuel combustion. The CR hydrogen heat release rate, a 12.35retard and 17.17 percent lower than the regular non-coated engine with CR hydrogen with LHR , was fuelled in ideal loading conditions.

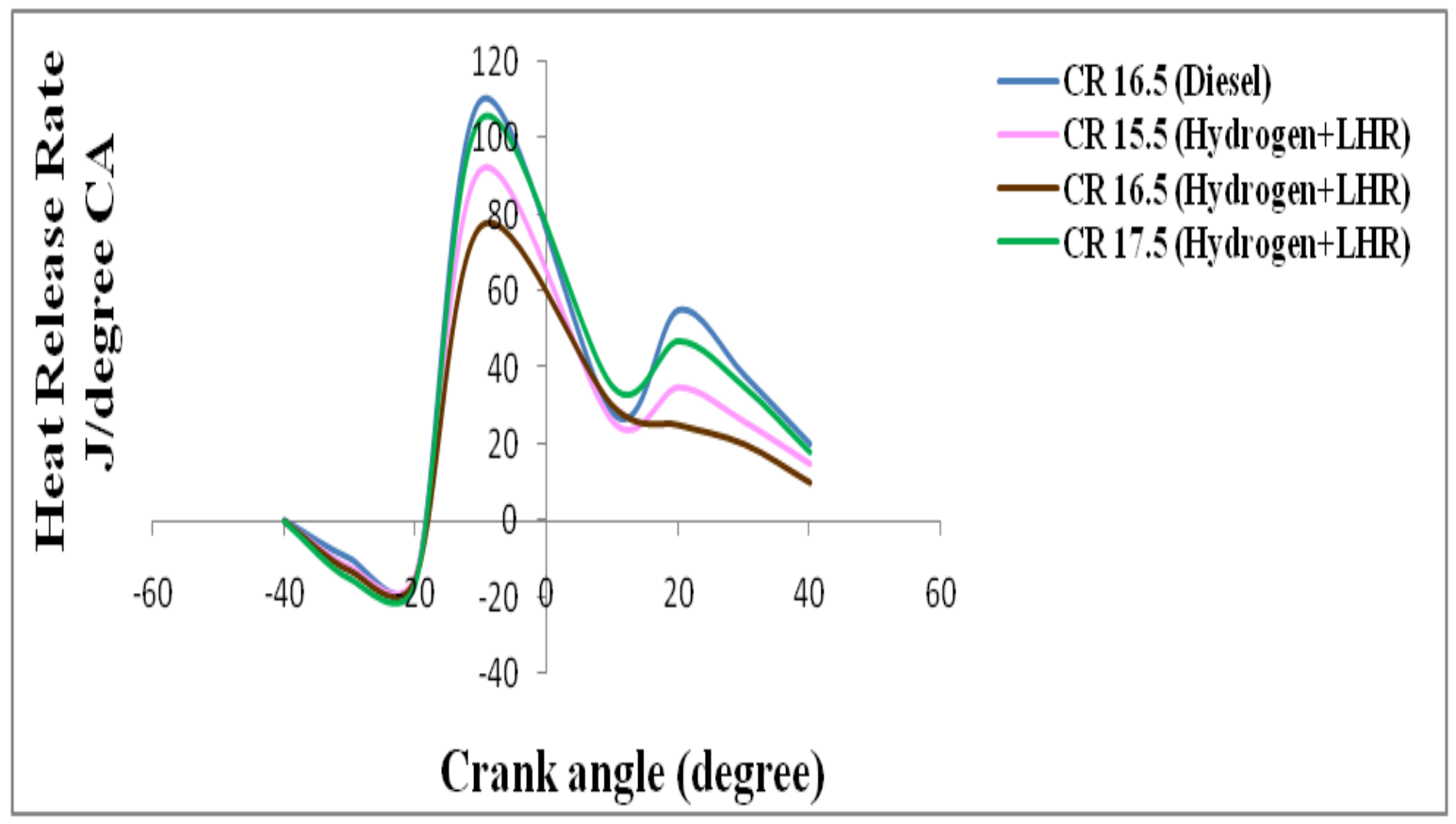

Figure 10.Crank angle vs Heat Release Rate

\section{Conclusion}

Hydrogen is a viable alternative fuel for CI engines. Particularly at compression ratio of 17.5 , better engine performance and lower emissions can be achieved without any change in engine modifications. Water-cooled direct injection and four-speed diesel engines have been tested with and without clean diesel coating, as well as CR Hydrogen + LHR We can draw the following inferences based on our findings. Hydrogen's specific fuel consumption is higher than diesel's, and the braking thermal efficiency is lower. In contrast to uncoated engines, the LHR engine's particular fuel consumption is low and the brake thermal efficiency is excellent.CO, HC and smoke emissions were reduced in CR Hydrogen + LHR, while NOx emissions were increased. Diesel-hydrogen releases heat at a lower rate than diesel during the combustion process. When compared to Hydrogen, the compression ratio during inflation and the duration of the combustion would be enhanced in comparison. 


\section{Reference}

[1] Azimov, U., Tomita, E., Kawahara, N. \& Harada, Y. 2011. Effect of syngas composition on combustion and exhaust emission characteristics in a pilot-ignited dual-fuel engine operated in PREMIER combustion mode. International Journal of Hydrogen Energy, 36, 11985-11996.

[2] Gatts, T., Liu, T., liew, C., Ralston, B., bell, V. \& Li, H. 2012. An experimental investigation of incomplete combustion of gaseous fuels of a heavy-duty diesel engine supplemented with hydrogen and natural gas. International Journal of Hydrogen Energy, 37, 7848-7859.

[3] Kapilan N., Mohanan P. and Reddy R.P., Performance and Emission Studies of Diesel Engine Using Diethyl Ether as Oxygenated Fuel Additive, SAE Paper number:200801 - 2466 (2008)

[4] Sahoo, B. B., Sahoo, N. \& Saha, U. K. 2012. Effect of H2:CO ratio in syngas on the performance of a dual fuel diesel engine operation. Applied Thermal Engineering, 49, 139-146.

[5] Saroj, C.D.; Dhirendra, K.A.; Ambica, N.T.; Mohanty, P. A review on performance of biogas and hydrogen onndiesel engine in dual fuel mode. Fuel 2020, 260, 116337

[6] Lešnik, L.; Kegl, B.; Torres-Jiménez, E.; Cruz-Peragón, F. Why we should invest further in the development of internal combustion engines for road applications. Oil Gas Sci. Technol. Rev. d'IFP Energies Nouv. 2020, 75, 56

[7] Kavtaradze, R.; Natriashvili, T.; Gladyshev, S. Hydrogen-Diesel Engine: Problems and Prospects of Improving the Working Process; SAE Technical Paper 2019-01-0541; WCX SAE World Congress Experience: Warrendale, PA, USA, 2019; p. 15, ISSN 0148-7191.

[8] Mansor, M.R.A.; Abbood, M.M.; Mohamad, T.I. The influence of varying hydrogenmethane-diesel mixture ratio on the combustion characteristics and emissions of a direct injection diesel engine. Fuel 2017, 190, 281-291.

[9] Luo, Q.; Sun, B. Experiments on the effect of engine speed, load, equivalence ratio, spark timing and coolant temperature on the energy balance of a turbocharged hydrogen engine. Energy Convers. Manag. 2018, 162, 12.

[10] Diaz, G.J.A.; Montoya, J.P.G.; Martinez, L.A.C.; Olsen, D.B.; Navarro, A.S. Influence of engine operating conditions on combustion parameters in a spark ignited internal combustion engine fueled with blends of methane and hydrogen. Energy Convers. Manag. 2019, 181, 10 .

[11] Iuga, A.N.; Popa, V.N.; Popa, L.I. Comparative Analysis of Automotive Products Regarding the Influence of Eco-Friendly Methods to Emissions' Reduction. Energies 2018, 12,6 .

[12] Millo, F.; Piano, A.; Peiretti Paradisi, B.; Marzano, M.R.; Bianco, A.; Pesce, F.C. Development and Assessment of an Integrated 1D-3D CFD Codes Coupling Methodology for Diesel Engine Combustion Simulation and Optimization. Energies 2020, 13, 1612. 